\title{
FIELD STUDY ON THE VENTILATION PERFORMANCE OF THE HYBRID TURBINE VENTILATOR (HTV) IN THE TROPICS
}

\author{
Mazran Ismail', Abdul Malek Abdul Rahman², Mohd.Rodzi Ismail ${ }^{3}$ \\ ${ }^{1}$ Research Scholar, School of Housing, Building \& Planning, Universiti Sains Malaysia, Penang \\ ${ }^{2,3}$ School of Housing, Building \& Planning, Universiti Sains Malaysia, Penang \\ Email: 'mazran79@hotmail.com
}

\section{Abstract}

The potential and effectiveness of the Hybrid Turbine Ventilator (HTV) application in actual building has been studied under Malaysian weather conditions. Tests for the ventilation performance of the device and other conventional ventilation strategies were carried out in the same room within a low-rise institutional building. A comparison through profiles of air temperature, relative humidity and indoor air velocity has been made to investigate the efficiency of the HTV in improving indoor thermal environment. The results show that the HTV succeeded to reduce indoor air temperature and relative humidity level by $0.7^{\circ} \mathrm{C}$ and $1.7 \%$ respectively. It also achieved to induce air movement at the occupied level of up to average of $0.38 \mathrm{~m} / \mathrm{s}$ in average for a three-day study with opened windows and doors. However, the relatively high air temperature, high relative humidity and minimal air velocity which are produced by the HTV when the openings are closed show that its performance should be enhanced by its utilization for the attic ventilation provided with the battery life is sufficient enough for its all time operation.

Keywords: Stack ventilation, Turbine ventilator, Solar energy, Malaysian climate

\section{INTRODUCTION}

Literature surveys on the turbine ventilator have shown that the device is quite successful to increase air change rate, ventilation rate (Lai, 2003) and releasing acid vapors from the working spaces (Mihailov et.al, 2001), especially in the windy region like temperate and cold climates. However, in the low-wind velocity condition, many studies (Lai, 2003; Ravel and Huynh, 2004) discovered that the fins of the turbine actually blocked the airflow in the connecting duct, resulting much lower rate of air extracted out from the ventilation duct as compared to an open stub. To overcome this problem, several studies on type and height of the turbine (West, 2005) and its form (Khan, 2008) have been done to find out the most efficient configuration of the turbine.

On the other hand, some researchers studied the impact of combining the turbine ventilator with the extractor fan. The results showed that it is effective to increase ventilation rate in the greenhouse (Porfirio, 2005) and achieving sufficient air change rate $(\mathrm{ACH})$ for the hygienic need in the bathroom ventilation system (Kuo and Lai, 2005). Following these studies, Lai (2006) discovered that the integration of turbine ventilator with solar-powered battery operated inner fan is successful to increase ventilation rate without consuming any paid energy. However, the result showed that the prototype only works optimally in low outdoor wind speed of not more than $5 \mathrm{~m} / \mathrm{s}$, thus demonstrated the limitations and problems of having a turbine which could possibly be a major resistance for much higher quantity of air extracted out by the inner fan below. In Malaysia, Azni et.al (2007) through their experimental study found that the combination of solarpowered turbine ventilator with a lightpipe is significant to improve both ventilation and daylighting condition.
In this field study, the authors aim to evaluate the potential and effectiveness of the Hybrid Turbine Ventilator (HTV) application under the real climatic condition of Malaysia. For this purpose, $3 \mathrm{HTV}$ s with new configuration of larger free outlet area provided on the top of the turbine are installed on the roof of an institutional building. The normal operating procedures of the room like windows and doors are opened and closed have been studied to find out its effectiveness in improving indoor thermal environment. The comparison with other ventilation strategies i.e. winddriven ventilation strategy and existing condition with natural ventilation has been made through the profiles of air temperature, relative humidity and air velocity.

\section{METHODOLOGY}

\section{A. The Case Study}

The case study is a 3-storey School of Biological Science three-storey building located on a sloping main campus site of Universiti Sains Malaysia (USM), Penang (Latitude $5^{\circ} 2^{\prime} \mathrm{N}$ and Longitude $100^{\circ} 2^{\prime} \mathrm{E}$ ). Built of conventional construction; concrete floor slab on grade and plastered single brick walls with metal pitch roof, the building represents a common construction building in Malaysia. However, there are various passive cooling design principles in used for ventilation purpose for their every single room, but not for reducing energy consumption. At one time, it was built energy consumption criteria was taken a backseat. One of the laboratories in the third (top) floor has been chosen as the case study. Highly glazed windows on north façade $\left(35.0 \mathrm{~m}^{2}\right.$ total area of openings) and a series of louvred windows $\left(12.0 \mathrm{~m}^{2}\right)$ with three doors $\left(7.5 \mathrm{~m}^{2}\right)$ on the opposite site promote the natural ventilation across much of the floor area. These openings form up nearly $7 \%$ larger than $10 \%$ openings to 
floor area ratio required by Malaysian Uniform Buildings By Laws (UBBL). However, due to its dense location with newly built academic buildings adjacent to it and the presence of the large vegetations, the room still suffered hot indoor air problems especially in the afternoon. Figure 1 below shows the configuration of the room.

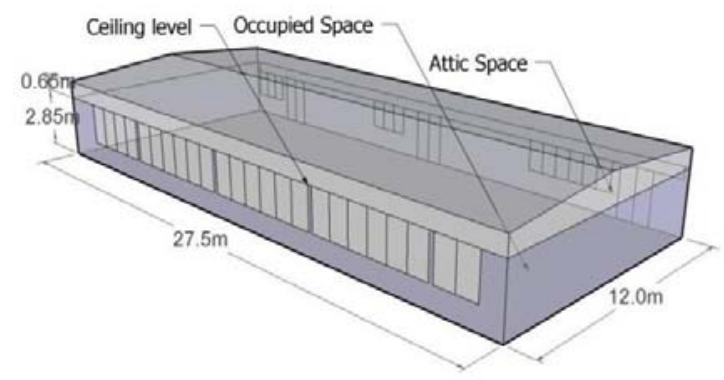

Fig. 1. Dimension and Configuration of the Room Studied

\section{B. Hybrid Turbine Ventilator (HTV)-A description}

The HTV is mainly fabricated by 18 " conventional turbine ventilator on the roof level, $\varnothing 35 \mathrm{~cm}$ aluminum ventilation duct (one meter height) to be placed in the attic space and a solar-powered extractor fan with $\varnothing 30 \mathrm{~cm}$ fan blade at the bottom. The proposed device is also applied with $\varnothing 20 \mathrm{~cm}$ inner duct in the turbine to allow higher rate of air extracted out through the larger free outlet area provided at the top (Figure 2).

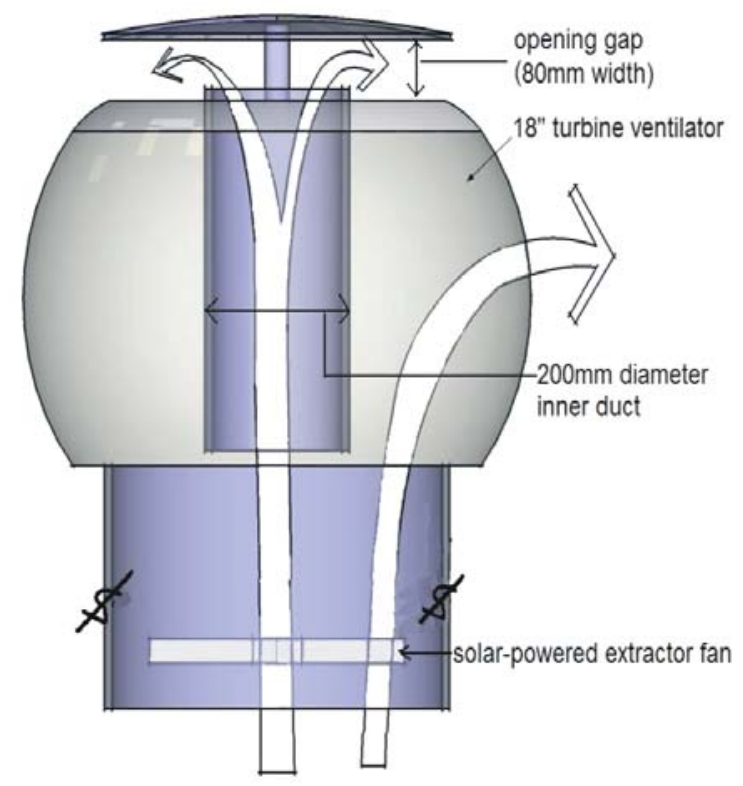

(a)

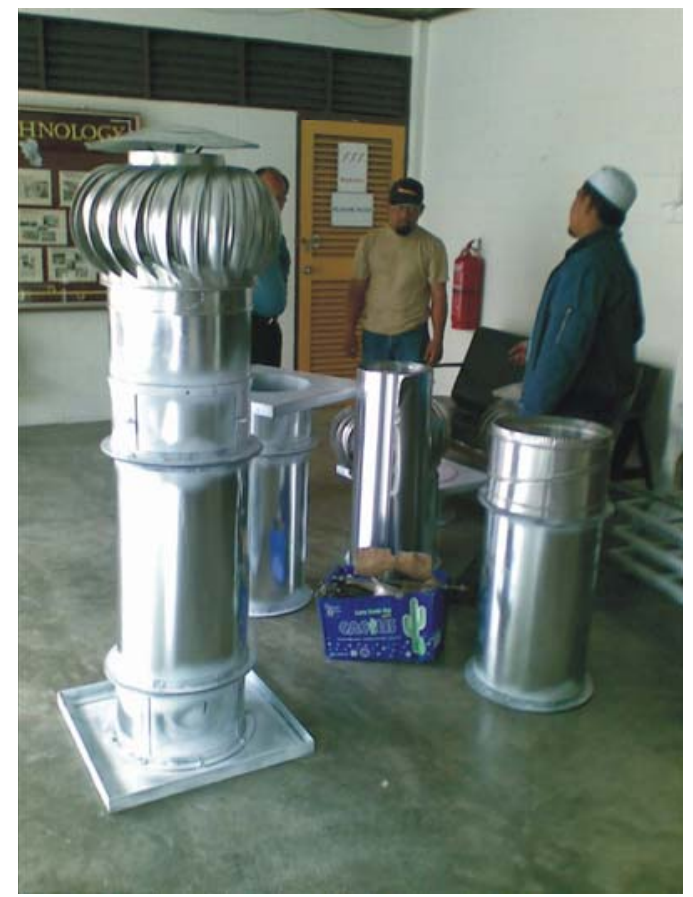

(b)

Fig. 2. Configuration of the HTV (a) Conceptual design (b) Actual size of the HTV

For this study, three sets of HTV were installed near the peak of the double pitch roof (Figure 3). The numbers and size of the turbine ventilators used were based on the manufacturer's suggestion through their manual guidelines for the specific volume of the room. 6 modules of solar panels ( 20 watts each) were placed nearby to power the extractor fan fixed at the ceiling level (Figure 4). Parallel to the pitch roof, the tilt angle of these PV panels was $5^{\circ}$ and totally exposed to the sun.

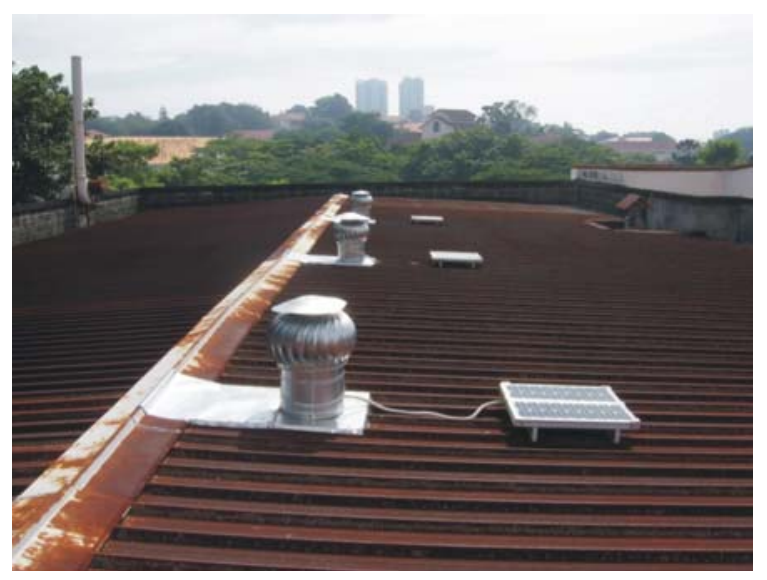

Fig. 3. HTV installed on the roof 


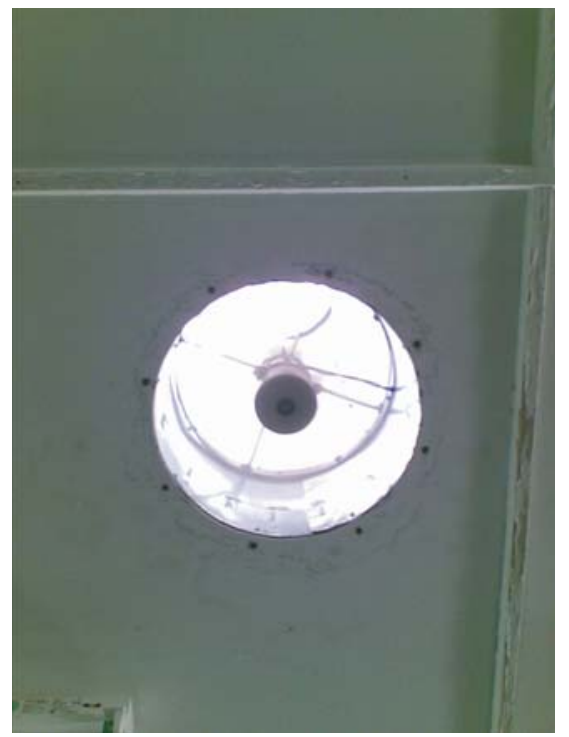

Fig. 4. Solar-powered extractor fan rotating at ceiling level

\section{Experimental Set-Up}

The field study was divided into three major experiments representing three different ventilation strategies i.e. i) existing condition with natural ventilation ii) with wind-driven turbine ventilator and iii) finally with the HTV. For each ventilation strategy, the measurement was taken for cases with and without openings. This is to investigate the actual impact of HTV on indoor thermal environment compared to other conventional strategies.

As each case study was done in different days corresponding with different weather conditions, the data of ambient conditions were also taken to compare with the internal conditions. The outdoor temperature and relative humidity were measured at a height of 1 meter above the (third) floor level and were placed in a box with lateral opening (for air circulation) to protect it from solar radiation. At the same time, the spectral pyranometer was placed on top of a parapet wall near the roof to measure the global solar radiation (Figure 5(a)).

For internal conditions, all sensors for temperature, air velocity and humidity were located in the middle of the room with a distance of $1.0 \mathrm{~m}$ above the floor (occupied level). Data from all sensors were recorded continuously for 3 clear days at 15 min intervals for each case onto a Babuc Data Logger (Figure 5(b)), which then were downloaded to a personal computer for further analysis. However, it should be highlighted here that since the windows and doors for 'opened' case could only be opened during $8.00 \mathrm{am}$ to $10.00 \mathrm{pm}$ due to security reason, the data analyzed in this study was based only on that period. This includes the analysis for the case of 'openings closed' to simplify comparison.

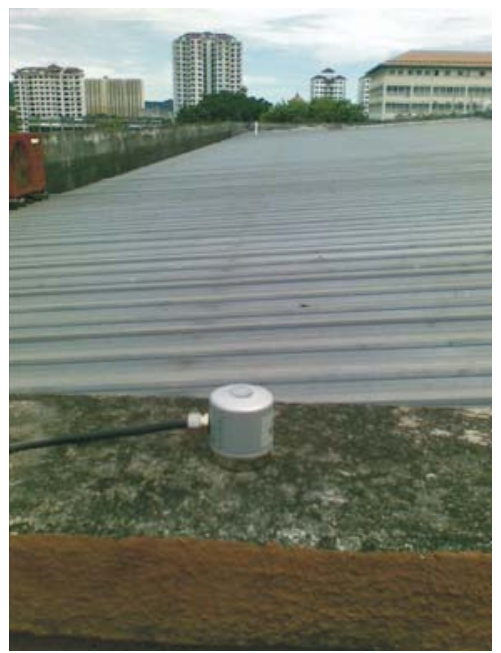

(a)

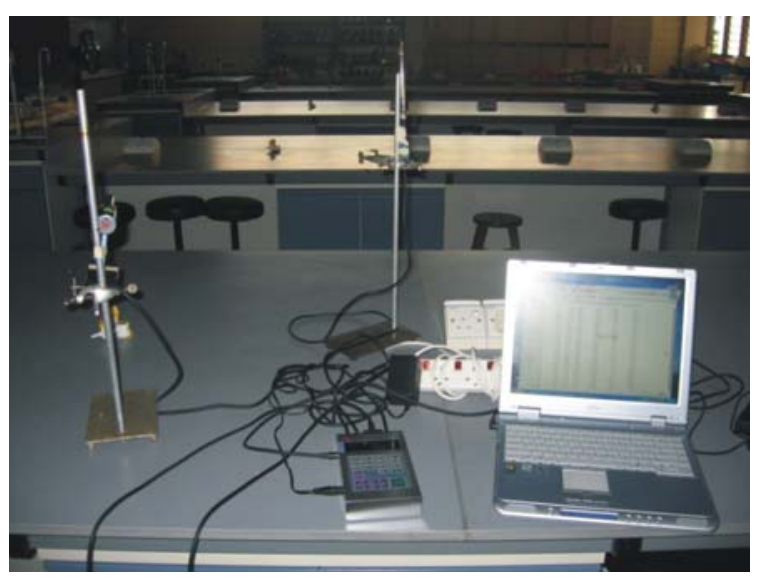

(b)

Fig. 5. Measurement equipments for data collection (a) Pyranometer (b) Babuc Environmental Data Logger

\section{RESULTS AND DISCUSSIONS}

\section{A. Air Temperature}

From the study, it was observed that the extractor fans at the ceiling level normally start to rotate at about $9.00 \mathrm{am}$ when there is sufficient intensity of incident solar radiation to generate electricity through the crystalline solar panels. The rotation rate of the fans then are increased with time to reach a maximum value between $12.30 \mathrm{pm}$ to $3.00 \mathrm{pm}$, although at times it stop rotating due to absence of sunlight. This condition clearly demonstrates that the crystalline PV panels used here are quite sensitive to the Malaysian cloudy sky conditions.

Figure 6 below shows the typical pattern of the increasing indoor air temperature in the closed room when 
the HTV is applied. It can be seen here that the higher extraction of hot air due to high solar radiation in the afternoon helps to decrease the higher peak temperature compared to the ambient. This shows the synergy of the HTV for decreasing indoor air temperature at the time when passive cooling is most needed in the building. But, when the solar radiation and external temperature go down, the occupied space still remains warm due to the heat stored in the attic.

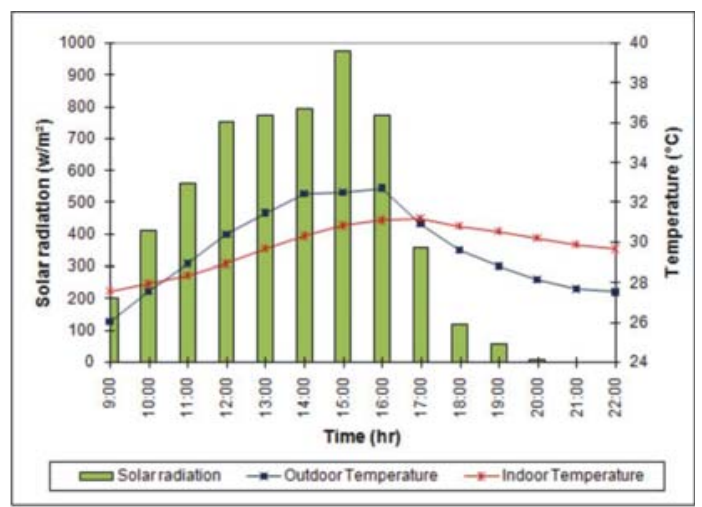

Fig. 6. Hourly variation of global solar radiation, outdoor temperature and indoor temperature on 24.5.08 with

HTV in windows and doors closed cases

However, in order to clearly demonstrate the impact of the HTV in reducing the indoor air temperature, comparison analysis with other ventilation strategies should be made. But, since the measurement for each case study has been done on different days with varying climatic conditions, the Relativeness Index which count on the data differences between indoor condition relatively to ambient (dT for temperature difference) was used here as a comparison tool to formulate general and subjective conclusions (Khedari et.al, 2000). Besides, the hottest days of each case study have also been chosen to make a simplified comparison analysis visualized by the graphs. Figure 7 shows the six days chosen which were almost have the same maximum peak temperature at around $1.00 \mathrm{pm}$ to $4.00 \mathrm{pm}$.

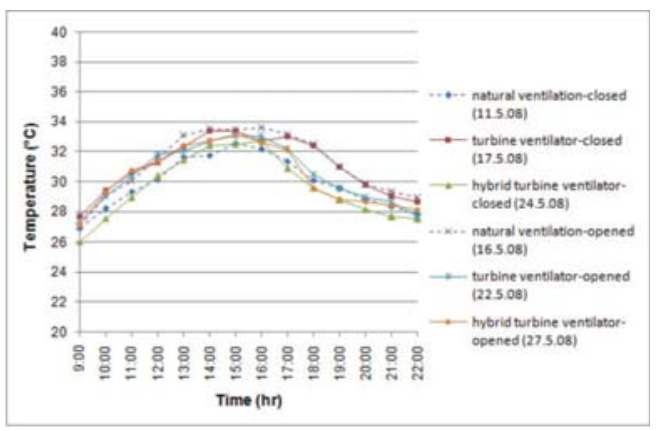

Fig. 7. Hourly variation of outdoor temperature during the hottest day of each case study for the windows and doors closed and opened cases
Figure 8(a) and Figure 8(b) below show the comparison of indoor-outdoor temperature differences between the hottest day of all the case studies. From both graphs representing both cases of with and without openings, it is clear that the HTV is more capable to reduce indoor air temperature relative to outdoor temperature than other ventilation strategies at most of the time except after the evening when the extractor fan is not rotating due no solar radiation.

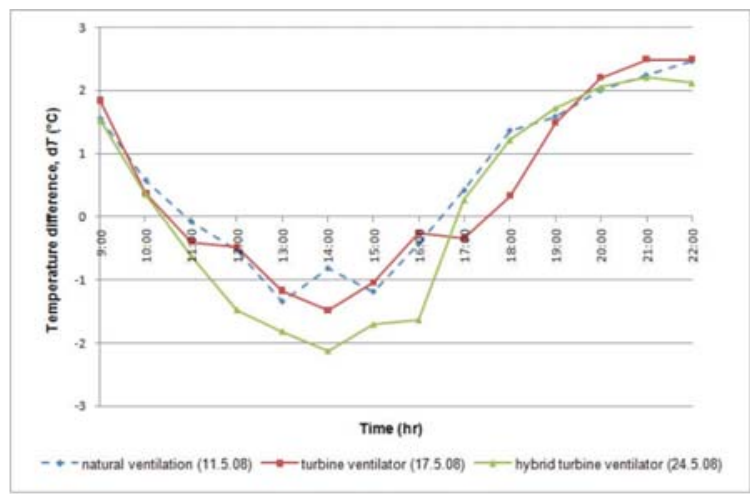

(a)

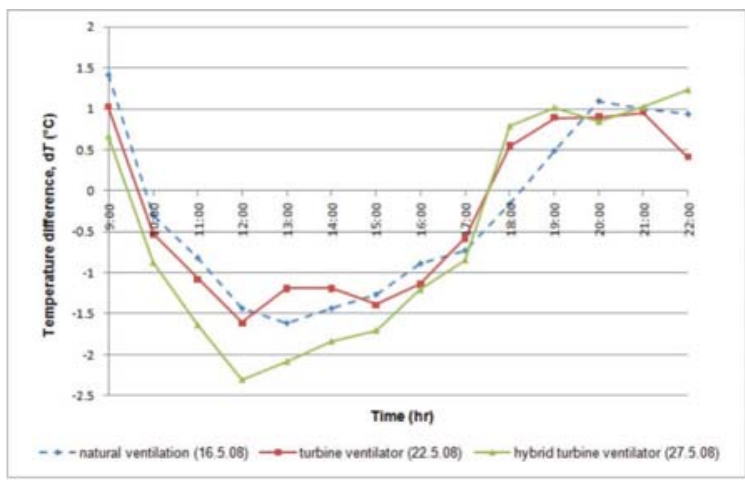

(b)

Fig. 8. Comparison of the difference between indoor and outdoor temperature for different ventilation strategies (a) windows and doors closed (b) windows and doors opened

On the other hand, the statistical results of the mean maximum, mean minimum and average temperature differences for 3 days measurement period of each ventilation strategies are represented by Figure 9 . By the graphs, it can be observed that the occupied space with the HTV shows higher reduction of air temperature relative to ambient, compared to other two ventilation strategies, with the mean minimum indoor-outdoor temperature difference recorded was $-1.9^{\circ} \mathrm{C}$ for the closed case and $2.3^{\circ} \mathrm{C}$ when the doors and windows are opened. This value is $0.7^{\circ} \mathrm{C}$ lower than mean minimum indoor-outdoor temperature difference recorded by natural ventilation for both cases. 


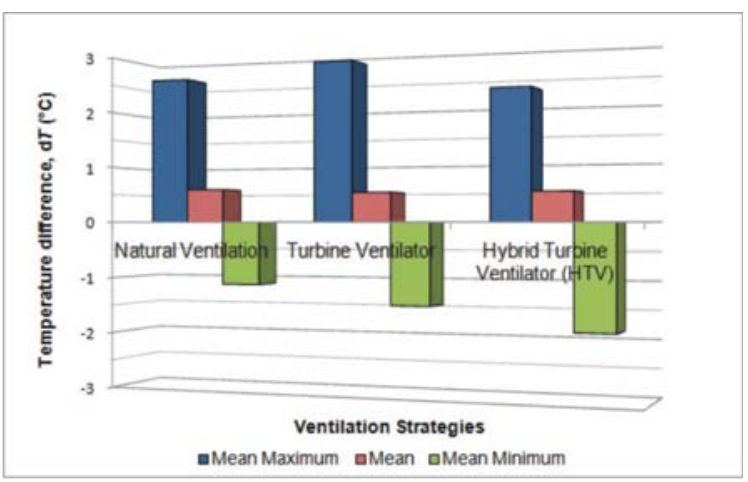

(a)

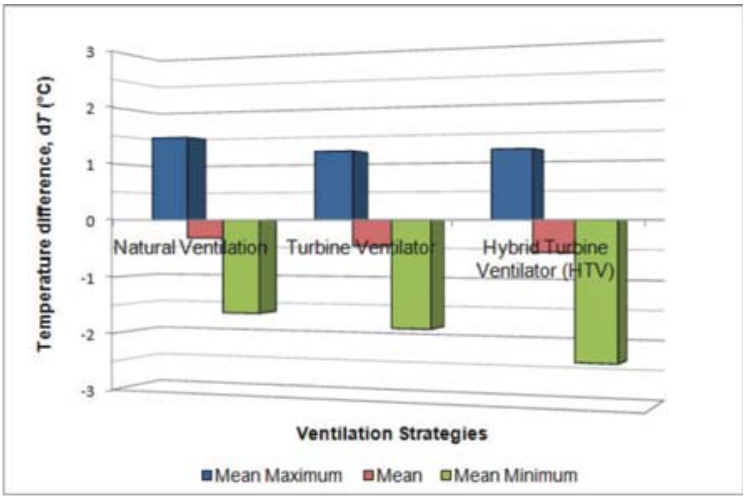

(b)

Fig. 9. Comparison of the mean maximum, mean minimum and average indoor and outdoor temperature difference for different ventilation strategies (a) windows and doors closed (b) windows and doors opened

However, although the mean maximum increment of indoor-outdoor temperature did not present much difference among all case studies, the application of HTV still show the lowest value, which is $0.3^{\circ} \mathrm{C}$ lower than natural ventilation for both cases of openings closed and opened. This demonstrates a contribution of the HTV to minimize higher peak temperature compared to the outdoor.

\section{B. Relative Humidity}

Investigating the impact of the HTV on reducing the level of indoor relative humidity is also very important in this climate since the high humidity reduces the body system ability to lose heat by evaporation, thus increase discomfort in this hot environment.

Based on Figure 10, it can be observed that the indoor relative humidity in the opened room with HTV application is generally lower than the outdoor and varies from approximately $52 \%$ to $75 \%$. The lowest value usually occurred during $1.00 \mathrm{pm}$ to $3.00 \mathrm{pm}$, became rapidly higher after the evening and reaching the highest value at $5.00 \mathrm{am}$ to $7.00 \mathrm{am}$.

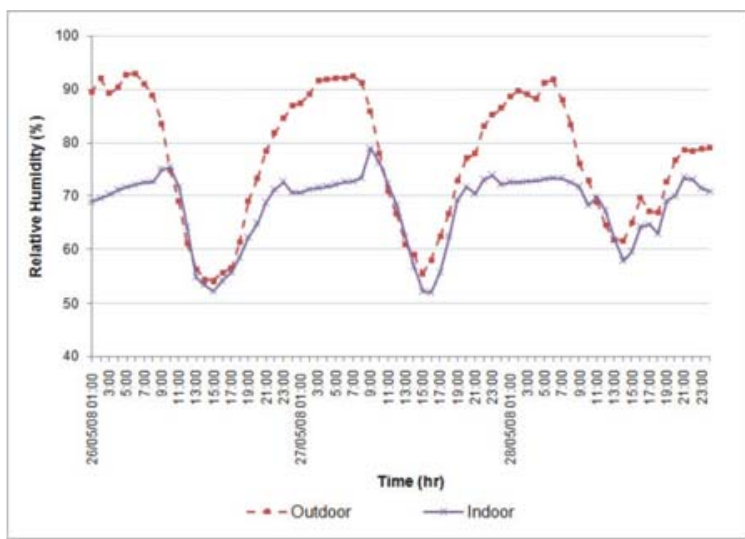

Fig. 10. Hourly variations of indoor and outdoor relative humidity for HTV for 3 day period (windows and doors opened)

However, it is quite interesting to note that after every $10.00 \mathrm{pm}$, the indoor relative humidity became suddenly lower due to the closed of the openings and became rapidly higher when the windows and doors are opened at $8.00 \mathrm{am}$. This demonstrate the problem of having doors and windows opened if the higher outdoor humidity coming in is not extracted out by the continuously operated turbine ventilator.

To clearly demonstrate the efficiency of the HTV during its operation, Figure 10 below shows its performance during the hottest day of the study compared to other ventilation strategies by using the Relativeness Index.

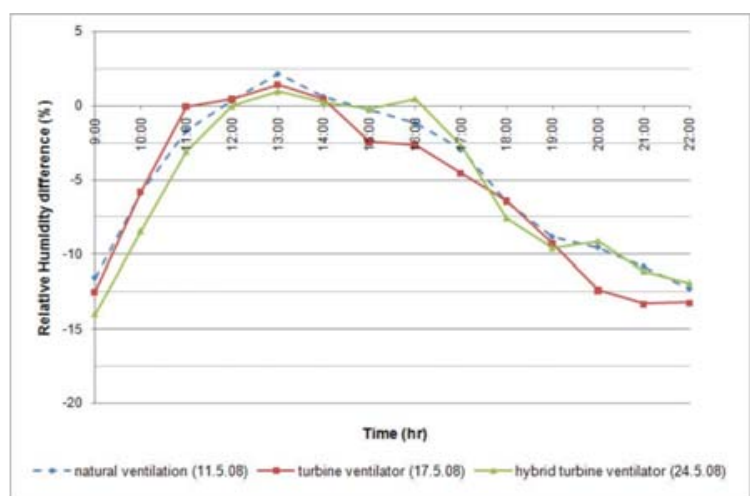

Fig. 11. Comparison of the difference between indoor and outdoor relative humidity for different ventilation strategies windows and doors closed

On the other hand, despite the inconsistent results obtained when the windows and doors are opened as shown in Figure 12(a), Figure 12(b) which represents the closed case shows a contradiction and has a more significant result as it is not very much influenced by the 
incoming outdoor humidity. From the graphs, it can be seen that from the three days period of study, the HTV is capable to reduce relative humidity by almost $1.7 \%$ compared to natural ventilation when the mean indooroutdoor relative humidity difference recorded was $-7.4 \%$, as only $-5.7 \%$ by natural ventilation. This value is expected to be increased if its operation after evening and during nighttime is ensured by providing a solar electricity storage system to power the extractor fan.

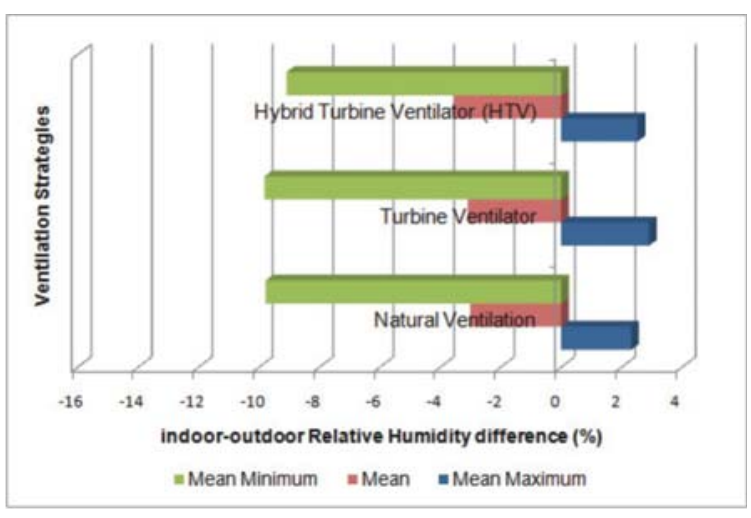

(a)

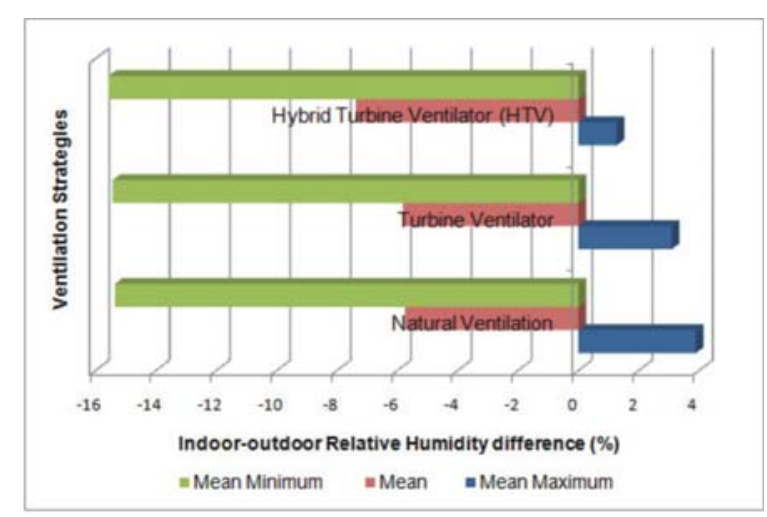

(b)

Fig. 12. Comparison of the mean maximum, mean minimum and average indoor and outdoor relative humidity difference for different ventilation strategies (a) windows and doors opened (b) windows and doors closed

\section{Air Velocity and Solar Radiation}

Regarding the indoor air velocity, it was found that when the openings are closed, the air velocity measured with all ventilation strategies are very minimal although sometimes HTV strategy succeeded to induce air speed exceeding $0.11 \mathrm{~m} / \mathrm{s}$, especially at the time of peak solar radiation (Figure 13). However, the mean maximum value of $0.10 \mathrm{~m} / \mathrm{s}$ recorded is obviously too low from the sufficient air movement of 0.25 to $1.0 \mathrm{~m} / \mathrm{s}$ required to improve thermal environment.

The failure of the HTV to generate ample air movement could be due to some reasons i.e. the relatively smaller size and number of the plastic extractor fan compared to the volume of the large room and also because of the height between the extractor fan (at the ceiling level) and sensors (at the occupied level) which is too far to feel the suction effect of the device.

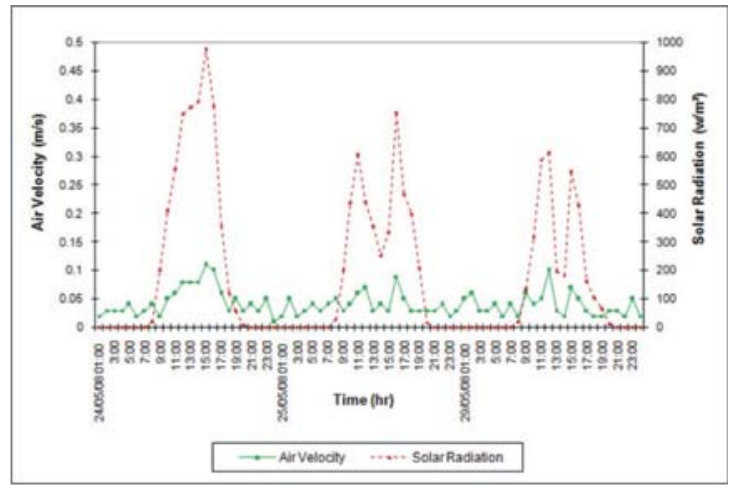

Fig. 13. Hourly variations of indoor air velocity and solar radiation for HTV for 3 days period (windows and doors opened)

However, the findings from the opened case study shows more positive results especially at the time of peak solar radiation when the HTV succeeded to produce average maximum air speed of $0.38 \mathrm{~m} / \mathrm{s}$ with the aid of cross ventilation (Figure 14). This value is quite promising since the case study is located in the dense built environment which could be a major constraint for effective natural cross ventilation to be produced in the normal condition.

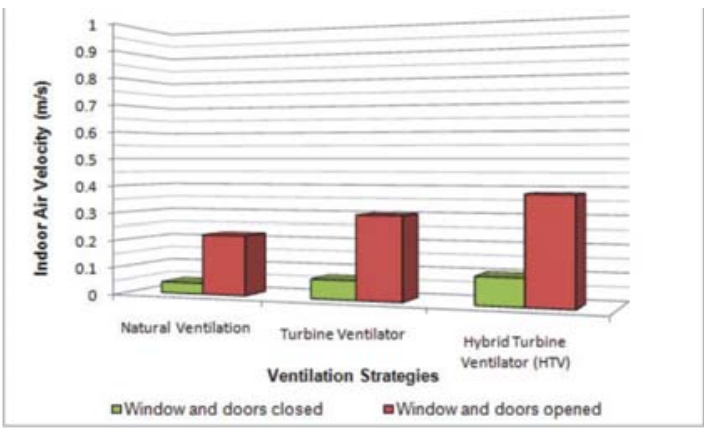

Fig. 14. Comparison of the mean maximum indoor air velocity for HTV with windows and doors closed and opened

\section{Discussion}

From the comparison analysis, it can be concluded that there is a potential for using HTV as an efficient stack ventilation device since the internal temperatures and 
relative humidity can be reduced by $0.7^{\circ} \mathrm{C}$ and $1.7 \%$, respectively compared to the natural ventilation strategy.

However, the relatively high indoor temperature, high relative humidity and minimal air velocity produced compared to the sufficient value needed for thermal comfort show that two major considerations for applying HTV in the climate of Malaysia arise, such as:

i) Prolongation of its operation during nighttime and in cloudy sky condition: From the study, it was found that the case with HTV application did not show the best internal condition all the time, especially when the sky is cloudy and at the end of solar radiation. No rotation of extractor fan during these times resulted in higher outdoor temperature and relative humidity entering the indoor space without a significant forced to extract it out. Therefore, this weakness should be remedied by using a battery for solar electricity storage to ensure its operation during all the time.

ii) Application of the HTV for attic ventilation: Application of the HTV to extract hot and humid air from occupied spaces alone was found to be inadequate to provide comfortable indoor environment for the occupants. Therefore, the use of HTV for attic space should be considered to ensure the dissipation of the hot air that is stored in that space, thus, reducing the heat radiated to the occupied space.

\section{CONCLUSION}

This field study has investigated the potential and effectiveness of the hybrid turbine ventilator (HTV) to improve indoor environment in a typical Malaysian building. The comparison with other two ventilation strategies i.e. wind-driven turbine ventilator and existing condition without any ventilator has been done to evaluate the efficiency of the HTV through the profiles of air temperature, relative humidity and air velocity. The results show that the HTV is significant to reduce the level of indoor air temperature and relative humidity up to $0.7^{\circ} \mathrm{C}$ and $1.7 \%$, respectively. However, the high average air temperature together with high relative humidity produced is considered too far from acceptable level for Malaysian thermal comfort conditions. The ability to induce air movement of up to $0.11 \mathrm{~m} / \mathrm{s}$ without the aid of the cross ventilation is also still much lower than sufficient air movement of $0.25-1.0 \mathrm{~m} / \mathrm{s}$ required to mitigate the adverse impact of high temperature and high humidity in providing comfortable indoor environment. However, the finding that shows its ability to help cross ventilation in providing average maximum air movement of $0.38 \mathrm{~m} / \mathrm{s}$ which occurred normally at the peak solar radiation is quite promising. This is also in line with the preferable custom of the people in tropical climate to open their windows during daytime. Therefore, in order to guarantee the high speed of fan rotation in this cloudy climate, it is suggested that the battery should be used to store the solar electricity, thus ensuring its operation in the evening. Providing the HTV for attic ventilation also seem to be very important to reduce the level of hot air radiated from the roof space. With these findings and suggestions, it is expected that this device could significantly improve indoor thermal environment of the Malaysian building.

\section{ACKNOWLEDGEMENT}

The authors would like to thank the Research Creative Management Office (RCMO), Universiti Sains Malaysia (USM) for the financial support provided for this research project.

\section{REFERENCES}

[1] Abdul Malek bin Abdul Rahman,1994, Design for natural ventilation in low-cost housing in tropical climates. Ph.D thesis, University of Wales College of Cardiff, Wales.

[2] Khan, N., Su, Y., Riffat, S., Biggs, C, 2008, Performance testing and comparison of turbine ventilators, Renewable Energy, 33, pp.2441-2247.

[3] Khedari, J, Waewsak, J, Thepa, S, Hirunlabh, J, 2000 , Ventilation impact of a solar chimney on indoor temperature fluctuation and air change rate in school building, Energy and Buildings, 32, pp.89-93.

[4] Kuo, I.S, and Lai, C.M, 2005, Assessment of the potential of roof turbine ventilators for bathroom ventilation, Building Services Engineering Research and Technology,26, pp.173-179.

[5] Lai, C.M, 2003, Experiments on the ventilation efficiency of turbine ventilators used for building and factory ventilation, Energy and Buildings, 35, pp.927-932.

[6] Lai, C.M, 2006, Prototype development of the rooftop turbine ventilator powered by hybrid wind and photovoltaic energy, Energy and Buildings, 38, pp.174-180.

[7] Mihailov, M., Dinchev, Z, Vlaseva, E., Petrov, T, Tenev, I, 2003, Forcing of natural ventilation in electrolytic shops. Annual, Vol.46, part II, Mining and Mineral Processing, Sofia, pp.147-152. 
[8] Porfirio, R, 2004, The uses of rotary turbine ventilator for controlling the air temperature and ventilation in greenhouse [Online], [Accessed 30th March 2007], Available from World Wide Web: http://www.teses.usp.br/teses/disponiveis/11/11143 /tde-25042005-170200/publico/rene.pdf

[9] Ravel, A. and Huynh, B.P, 2004, Characterizing roof ventilators: In: The 15th Australasian Fluid Mechanics Conference, 13-17 December 2004, The University of Sydney, Sydney, Australia.

[10] West, S, 2005, Natural ventilation flow rate performance and product development: In The Queensland University of Technology Research Week International Conference, 4-5 July, Brisbane, Australia.

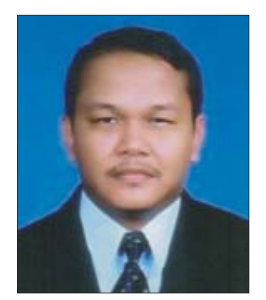

Mazran Ismail is a research scholar in Architecture (Energy) at the School of Housing, Building \& Planning, Penang and a Fellowship holder. He received his B.Sc(HBP), Bachelors in. Architecture and M.Sc in Housing from the Universiti Sains Malaysia. His main research interests are climatic responsive architecture, low energy ventilation technologies and thermal comfort studies in tropical building. 